\title{
An Update on Endoscopic Management of Post-Liver Transplant Biliary Complications
}

\author{
Hyun Woo Lee ${ }^{1}$, Najmul Hassan Shah ${ }^{2}$ and Sung Koo Lee ${ }^{1}$ \\ ${ }^{1}$ Division of Gastroenterology, Department of Internal Medicine, Asan Medical Center, University of Ulsan College of Medicine, Seoul, \\ Korea, ${ }^{2}$ Division of Gastroenterology and Hepatology, Liver Transplant Program, Shifa International Hospital Ltd., Shifa College of Medicine, \\ Islamabad, Pakistan
}

Biliary complications are the most common post-liver transplant (LT) complications with an incidence of $15 \%-45 \%$. Furthermore, such complications are reported more frequently in patients who undergo a living-donor LT compared to a deceased-donor LT. Most post-LT biliary complications involve biliary strictures, bile leakage, and biliary stones, although many rarer events, such as hemobilia and foreign bodies, contribute to a long list of related conditions. Endoscopic treatment of post-LT biliary complications has evolved rapidly, with new and effective tools improving both outcomes and success rates; in fact, the latter now consistently reach up to $80 \%$. In this regard, conventional endoscopic retrograde cholangiopancreatography remains the preferred initial treatment. However, percutaneous transhepatic cholangioscopy is now central to the management of endoscopy-resistant cases involving complex hilar or multiple strictures with associated stones. Many additional endoscopic tools and techniques-such as the rendezvous method, magnetic compression anastomosis, and peroral cholangioscopy_combined with modified biliary stents have significantly improved the success rate of endoscopic management. Here, we review the current status of endoscopic treatment of post-LT biliary complications and discuss conventional as well as the aforementioned new tools and techniques. Clin Endosc 2017;50:451-463

Key Words: Liver transplantation; Biliary tract diseases; Choledocholithiasis; Anastomotic leak; Cholangiopancreatography, endoscopic retrograde

\section{INTRODUCTION}

Despite improvements in surgical techniques, biliary complications following liver transplant (LT) surgery remain a major cause of morbidity and mortality. Furthermore, the reported incidence of post-LT bile duct complications varies widely from $5 \%$ to $45 \% .^{1-3}$ There are many reasons for this disparity: (1) graft and LT type, including deceased-donor LT (DDLT) or living-donor LT (LDLT); (2) type and number of

Received: September 29, 2016 Revised: February 16, 2017

Accepted: February 22, 2017

Correspondence: Sung Koo Lee

Division of Gastroenterology, Department of Internal Medicine, Asan Medical Center, University of Ulsan College of Medicine, 88 Olympic-ro 43-gil, Songpa-gu, Seoul 05505, Korea

Tel: +82-2-3010-3186, Fax: +82-2-476-0824, E-mail: sklee@amc.seoul.kr

(cc) This is an Open Access article distributed under the terms of the Creative Commons Attribution Non-Commercial License (http://creativecommons.org/ licenses/by-nc/3.0) which permits unrestricted non-commercial use, distribution, and reproduction in any medium, provided the original work is properly cited. donor bile ducts involved, especially in cases of LDLT; and (3) anastomosis type, including choledocho-choledochotomy (CC) or hepaticojejunostomy (HJ).

Biliary complications are generally more common after LDLT than after DDLT because the reconstruction of low-caliber and small ducts is more complex in LDLT and often requires one to four donor ducts. ${ }^{4}$ This is accompanied by a proportional increase in the risk of biliary complications. Furthermore, the reconstruction type of the donor bile duct within the recipient is also important. In particular, CC preserves the sphincter of Oddi, allowing easy endoscopic access and management of post-LT biliary complications. In contrast, HJ restricts the endoscopist's ability to perform post-LT endoscopic evaluation of the biliary system using traditional tools, and specialized scopes or alternative access routes are required instead. ${ }^{5}$

A variety of bile duct complications have been recognized and reported, with the list increasing as LT becomes more 
common. Nonetheless, bile duct strictures, leaks, stones, sludge, and casts comprise the bulk of post-LT biliary complications. Other less common but important bile duct-related complications include hemobilia, foreign body-like suture materials, ampullary dysfunction, mucocele, and cholangitis.

In the early days of the LT era, because endoscopic outcomes were suboptimal, intervention radiology and surgery were the mainstay of post-LT management of biliary complications. More recently, endoscopic tools and techniques have consistently improved, expanding the role of endoscopic management of post-LT biliary complications; owing to the excellent outcomes and consistent success rates, endoscopic management is now the accepted standard of management in most cases. Indeed, intervention radiology and surgery are now performed in only a small percentage of cases in which endoscopy fails or if a specific indication warrants such treatment. $^{6-10}$

Here, we review the current status of endoscopic management of post-LT biliary complications by focusing on both conventional as well as new and evolving endoscopic tools and techniques that have become available in recent years and led to significantly improved outcomes.

\section{ENDOSCOPIC MANAGEMENT OF SPECIFIC COMPLICATIONS}

\section{Biliary strictures}

Biliary strictures remain a common challenge after LT despite improvements in techniques and learning curves. The incidence of biliary strictures is more common after LDLT (28\%-32\%) than after DDLT (5\%-15\%) because anastomoses involving small-caliber peripheral donor ducts are more complex in LDLT. Biliary strictures are less common among the living donor population (0.5\%); nonetheless, they are extremely important to recognize and manage appropriately. After LDLT, because living donors sometime require re-hospitalization for further endoscopic treatment or Roux-en-Y biliary reconstruction due to complications, death from liver failure rarely occurs. ${ }^{11,12}$ Therefore, this is an important issue for the wider application of LDLT.

These strictures are traditionally categorized into two main morphological types: anastomotic strictures (ASs) and non-anastomotic strictures (NASs); this classification is still accepted and useful for most patients. ASs are single, shorter, localized to the anastomotic site, and have an incidence of $4 \%-9 \%$; they are thought to develop as a result of (1) localized fibrosis caused by operative techniques; (2) compromised local microcirculation in the bile duct; or (3) associated bile leaks. ${ }^{13}$ Conversely, NASs are usually longer, multiple, more proximal- ly located (near the hilum or intrahepatic ducts [IHDs]), and located proximal to the actual anastomosis in the donor's bile ducts. They have an incidence of 5\%-15\% in DDLT and are especially common in cases of donation after cardiac death transplant (20\%-33\%). They usually present late with a mean time to presentation of 3.3-5.9 months post-orthotopic LT (OLT). However, in a significant number of patients, the morphology and complexity of these strictures do not follow such traditional patterns. Secondary complicating factors-such as stasis, sludge, and stones proximal to the strictures-lead to low-grade cholangitis, which in turn has secondary local effects on the classical stricture patterns, causing many more strictures to develop spontaneously in more proximally located IHDs. The classical strictures (ASs and NASs) are usually responsive to traditional endoscopic techniques, while these complex secondary events present challenges including endoscopic failure. Ultimately, such cases require rare radiological or surgical interventions, including new grafts.

We fully agree with the views of previous reviewers that a conscious effort by the attending endoscopist to ascertain the full operative details of the biliary and liver anatomy is important. ${ }^{14}$ In this regard, the pre- and peri-operative radiological images of individual donor biliary anatomy as well as the operative details of biliary reconstruction must be fully used. The endoscopist must comprehend and memorize the individual images before starting the endoscopic management of post-LT biliary complications. A detailed review of the pre-intervention magnetic resonance cholangiopancreatography (MRCP) images, if available, makes it possible to know which tools may be necessary for the pathological morphology before the procedure. We believe that this is one of the most important factors improving the outcomes of individual procedures.

In both DDLT and LDLT patients with duct-to-duct anastomosis, the bile duct is usually accessed via traditional endoscopic retrograde cholangiopancreatography (ERCP) using conventional side-viewing endoscopes. However, in some post-LT patients, especially in the post-LDLT context, even reaching the duodenum involves a learning curve. The technique necessitates position changes and intra-abdominal pressure to manipulate the scope into the descending duodenum. Additionally, endoscopic access to patients with surgically altered anatomy-by Roux-en-Y HJ or Roux-en-Y gastric bypass-requires deep ERCP techniques and modifications thereof. Several studies have been published in this regard with variable success rates. Furthermore, each has had different limitations on its use in post-LT settings, focusing on pediatric colonoscopy, double-balloon enteroscopy (EN450P5; Fujinon, Saitama, Japan), single-balloon enteroscopy (SIF-Q260; Olympus, Tokyo, Japan), spiral enteroscopy over- 

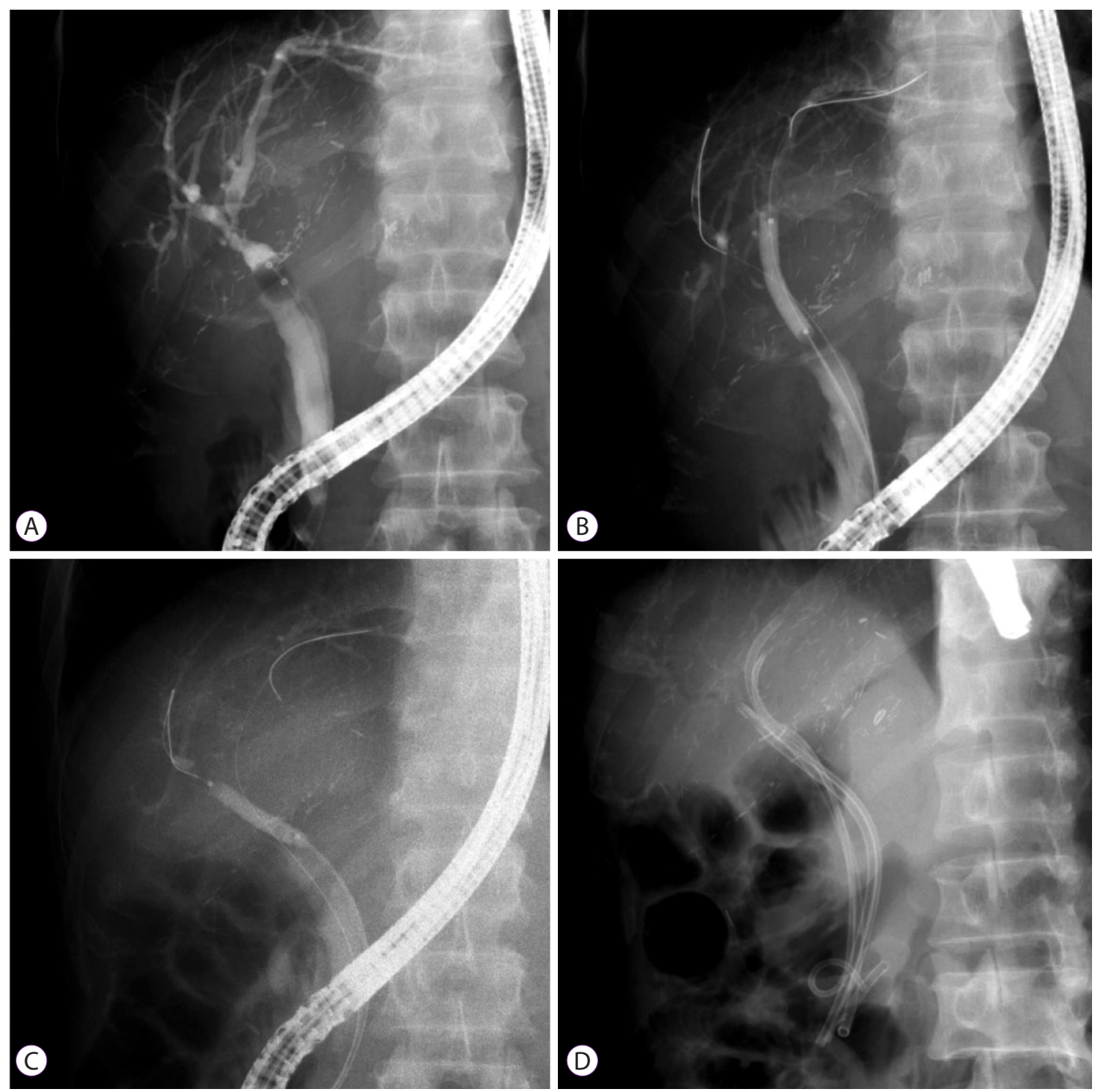

Fig. 1. Cholangiogram of an anastomotic stricture (AS) in a 50-year-old man after living-donor liver transplant. (A) AS on a balloon-occluded cholangiogram. (B, C) Double guide wires inserted through the biliary stricture and balloon dilatation (4 mm at $10 \mathrm{~atm}$ ). (D) Four plastic stents inserted through the AS of the transplanted liver.

tube (Endo-Ease Vista ${ }^{\circledR}$; Spirus Medical, Stoughton, MA, USA), or surgical or endoscopic ultrasonography-guided percutaneous gastrostomy followed by conventional ERCP through the gastrostomy port (in patients with Roux-en-Y gastric bypass anatomy). ${ }^{15-20}$

Percutaneous transhepatic cholangioscopy (PTCS), the most recent upgrade to the endoscopic management of bile duct complications in post-LT patients, provides access to the biliary system through percutaneous ports created by an interventional radiologist. This is an effective and safe intervention that substantially improves outcomes in select patients with (1) previously challenging post-LT bile-duct access problems or (2) complications that previously required more risky radiological or surgical interventions. In addition, the development and routine use of many endoscopic tools and techniques have substantially improved. This has improved bile-duct access and effective management of difficult bile-duct strictures with complex and mixed pathologies.

The success rate of endoscopic therapy of the bile duct is $80 \%-100 \%$ in cases of OLT, although some complex hilar and intrahepatic strictures have success rates within the lower end of this range, especially in cases of LDLT. ${ }^{14}$ Nonetheless, success rates are consistently well above $80 \%$ in most patients, even in the post-LDLT setting, due to the availability of new access approaches and techniques.

Endoscopic management of bile-duct strictures via conventional, deep endoscopy, or percutaneous routes involves standard guide wire access across the stricture, followed by sphincterotomy, balloon dilation, and/or biliary stenting of the stricture. ${ }^{14,21,22}$ Most patients with classical ASs require se- 

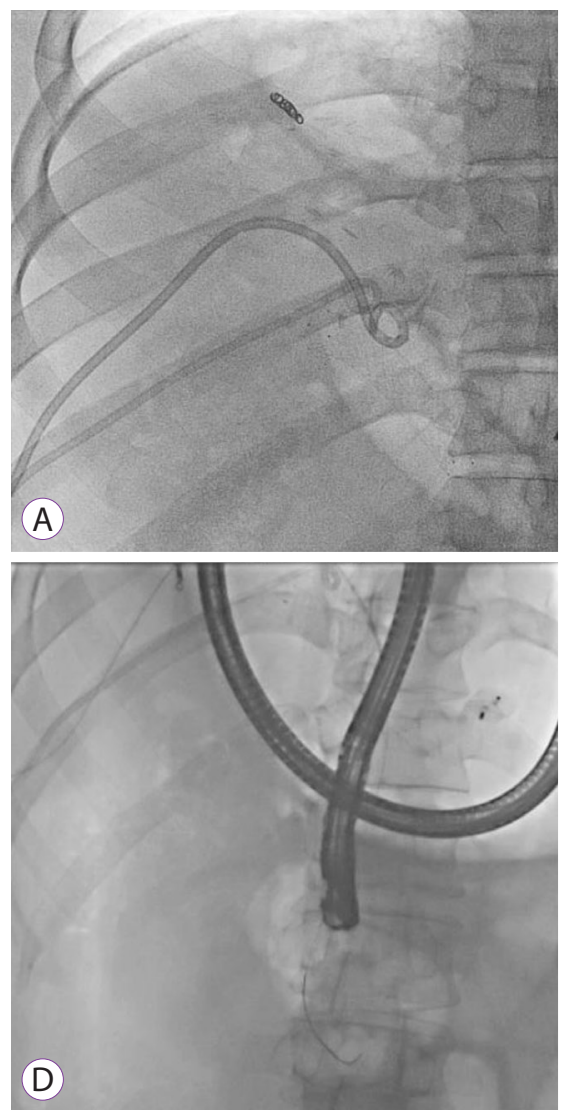
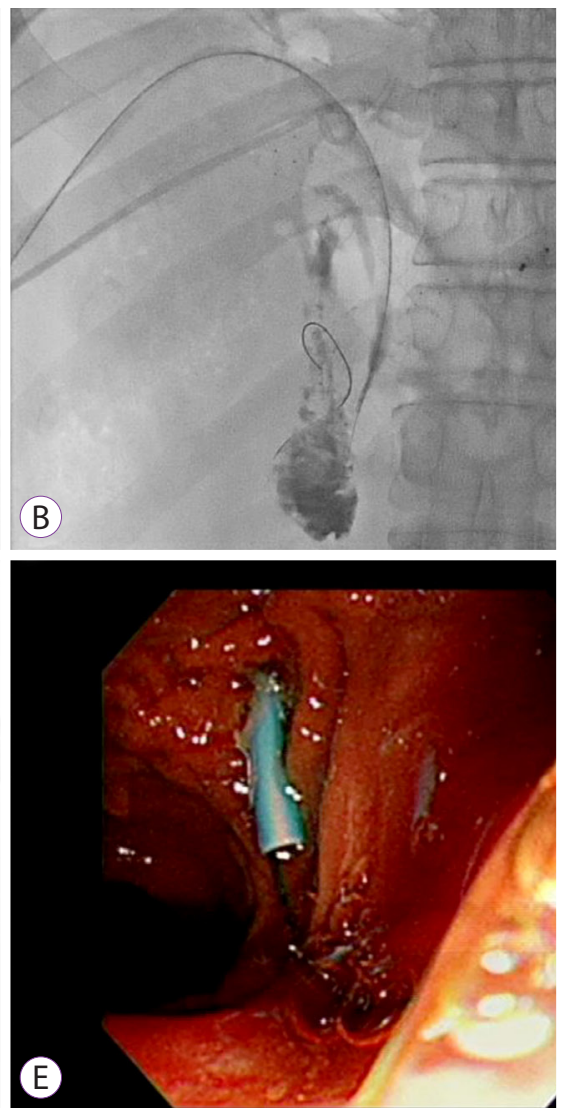
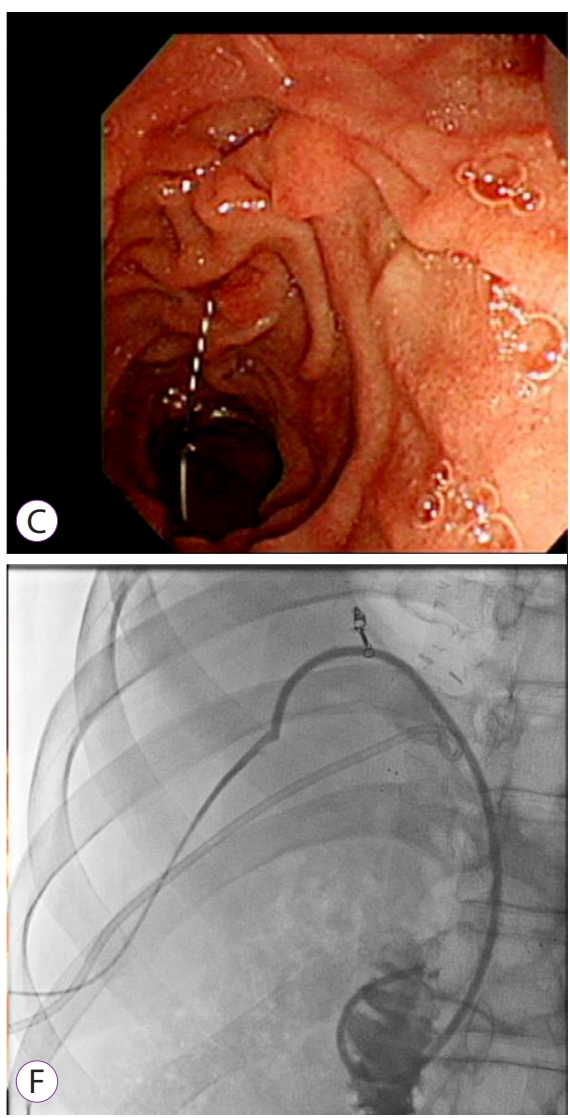

Fig. 2. The rendezvous technique in a 47-year-old man with failed guide wire access across an anastomotic stricture (AS) after living-donor liver transplant. (A, B) Percutaneous transhepatic cholangiogram showing a high-grade stricture at the biliary anastomosis site and the guide wire inserted through the transhepatic tract. (C, D) Endoscopic retrograde cholangiopancreatography view of the guide wire passed through the ampullary orifice from the percutaneous tract. (E, F) Plastic stents inserted through the AS.

rial procedures that involve balloon dilation, followed by the placement and exchange of plastic stents over a period of at least 1 year. Several reports have claimed that balloon dilation alone is effective. However, there is now a consensus that dilation alone is less effective than balloon dilation with biliary stenting. ${ }^{22-26}$ At this point, we must emphasize that balloon dilation should be avoided in early strictures as well as those associated with bile leaks to avoid anastomotic disruption. The frequency and timing of follow-up in serial procedures has been a subject of debate: some have suggested that an accelerated course with more early interventions and fewer longer intervals between procedures achieves equivalent results. However, in our view, such scheduling should be individualized. Under normal circumstances, we would recommend the accepted average of 2-3-month intervals; this way, endoscopists avoid stent occlusion and the risk of cholangitis.

Moreover, there is general agreement that multiple stents are preferable to single stents. A more aggressive strategy of placing the maximum number of stents (three to four 10-Fr stents depending on stricture location and proximal bile duct size) with follow-up evaluations at 3-5-month intervals as well as further dilation and stent exchanges has shown a more than $90 \%$ success rate with complete morphological stricture resolution in patients with ASs (Fig. 1). ${ }^{13,27}$ Indeed, an even further modified and aggressive approach has been described with better resolution of the stricture and few side effects when the maximum number of stents (up to nine) are placed following initial balloon dilation; the approach also involves on-demand repeat procedures (subject to evidence of cholangitis or stent occlusion). One study that used this approach reported that a median of three ERCP procedures were performed per patient over a median duration of 15 months and that complete resolution was achieved in $94 \%$ of patients at a median follow-up of 11 months. ${ }^{28}$

Uncovered metal stents are typically contraindicated in post-transplant settings because of previously described factors. ${ }^{29}$ In contrast, covered self-expanding metal stents (CSEMSs) have been a subject of interest in the treatment of post-LT biliary strictures that are refractory to conventional treatment mainly because such stents have a large diameter (30 Fr for a 10-mm stent) and a potential longer patency. ${ }^{29-32}$ One study reported a success rate of $87.5 \%$ (14/16 patients) at 
10 months follow-up, although there was a high rate of stent migration and the technique was of limited use in post-LDLT patients. ${ }^{32}$ To overcome the common problem of stent migration while retaining the advantages of larger lumens and patency rates with good outcomes, several reports have used short-length CSEMSs combined with specialized external anchoring assemblies (GORE Viabil ${ }^{\circledR}$; ConMed, Utica, NY, USA) and anti-migration waists (Niti-S $\mathrm{S}^{\mathrm{mm}}$ and $\mathrm{KAFFES}^{\mathrm{mm}}$; Taewoong, Gimpo, Korea) in post-LT settings. ${ }^{31}$ However, although these reports suggest that such instruments play a positive role in selected patients at anatomically suitable locations, some researchers have reservations about case selection, suggesting that traditional multiple plastic stents (MPSs) could have achieved the same results. ${ }^{33}$ In another study comparing stricture resolution rates between MPSs and self-expanding metal stents (SEMSs), SEMSs did not have a clear advantage over MPSs. ${ }^{34}$ Additionally, SEMSs are less likely to be beneficial in complex hilar and more proximal strictures, especially in the LDLT context, because space is limited in proximal bile ducts. Further experience and data are needed to better evaluate the usefulness of metal stents in treating post-LT biliary strictures.

Bile duct strictures involving the hilum and more proximal IHDs, including the proximal ASs and NASs, are more challenging than those located more distally. One major challenge in managing such strictures is access past the stricture, either up-stream into the proximal bile ducts from below the distal bile ducts or into the enteric lumen across tightly stenosed and tortuous strictures via the transhepatic route. In this regard, swing-tip catheters are extremely useful for selective cannulation of the angled, tightly closed anastomosed strictures in the segmental ducts. Similarly, two-in-one ductoplasties or multiple-duct anastomoses are usually difficult to access using a traditional cannula. In such cases, sphincterotomies and balloons are also used for wire access.

Likewise, a rendezvous technique may be used to achieve selected duct access when the traditional route fails, especially in patients with angulated or tortuous strictures. Such a hybrid technique combines the percutaneous transhepatic and endoscopic transpapillary approaches (Fig. 2). ${ }^{35,36}$ Many studies have demonstrated that the rendezvous technique is useful and safe for the management of biliary stricture after LDLT. In addition to this classical method, various modified techniques have been attempted using a metal ball-tip cannula (StarTipV; Olympus, Tokyo, Japan) and Kumpe catheter $\left(\right.$ Beacon $^{\circledR}$; Cook Medical, Bloomington, IN, USA). ${ }^{37}$

Aside from these access-related issues, the small caliber of more proximal extra- or intrahepatic bile ducts may limit the caliber and number of stents that can be placed. Such cases require multiple procedures, and sometimes, permanent indwelling stents and catheters. There have been some en- couraging results showing successful endoscopic treatment of such difficult and complex strictures. However, a standardized therapeutic approach is yet to be identified and the outcomes are still less than satisfactory. ${ }^{14}$ One study suggested that balloon dilation alone has greater efficacy ( $91 \%$ vs. $31 \%)$ and lower rates of cholangitis ( $12 \%$ vs. $25 \%$ ) than balloon dilatation with stenting in the case of NASs. ${ }^{38}$ Conventional polyethylene stents are relatively rigid, do not have side holes, and can occlude secondary branch ducts. Stent migration is also a risk that can result in intestinal perforation. Such limitations are the usual causes of poor results using conventional plastic stents to treat NASs. In this regard, one recent study reported a modified approach to the management of NASs. Specifically, the study authors combined balloon dilation with multiple specialized biliary stents. Large-caliber (8.5-10 Fr), long (12-20 $\mathrm{cm}$ ), highly flexible, fenestrated stents with multiple side holes (Johlin ${ }^{\text {Tw }}$ Pancreatic Wedge Stent; Cook Medical, Bloomington, IN, USA) were placed deep into the IHD. The stents were thought to allow adequate bile drainage through their multiple side holes as well as via the inter-stent space. Moreover, the anchoring effect of the upstream wedge end meant that there was very little risk of migration. ${ }^{14}$

Single-operator peroral cholangioscopy (POCS) using the SpyGlass ${ }^{\circledR}$ Direct Visualization System (Boston Scientific, Marlborough, MA, USA) is effective for successful guide wire placement in patients with biliary strictures by allowing direct visualization of the inner wall of bile ducts. In addition, a pinhole orifice can be visualized at the stricture site. Recent studies have reported that this technique is feasible and can be performed successfully in both pre- and post-OLT patients with no complications. ${ }^{39,40}$ Similarly, PTCS is an effective treatment option in the case of benign ASs. It allows direct visualization of the biliary system and enables identification and treatment of intraductal lesions; in this way, it has an advantage over ERCP. ${ }^{41}$ In cases of post-LT biliary strictures, PTCS has been used when duct access is endoscopically difficult (e.g. in Roux-en-Y HJ patients) as well as in patients with an intractable stricture that cannot be traversed using a retrograde approach or rendezvous access combined with ERCP. One study reported that PTCS treatment in cases of benign bilio-enteric ASs had an initial technical success rate of $100 \%$ and that the overall success rate was $81 \% .{ }^{42}$ Recently, the combination of endoscopic and percutaneous transhepatic radiologic interventions has had an increasing role, especially in patients with multiple intrahepatic biliary strictures. The percutaneous balloon dilatation and catheter maintenance method for post-LT biliary strictures has a $92 \%$ technical success rate, and $84 \%(10 / 12)$ of patients preserved bile duct patency for a mean 19 months. ${ }^{43}$ Similarly, PTCS and the placement of internal-external stents may play a role in relieving jaundice 

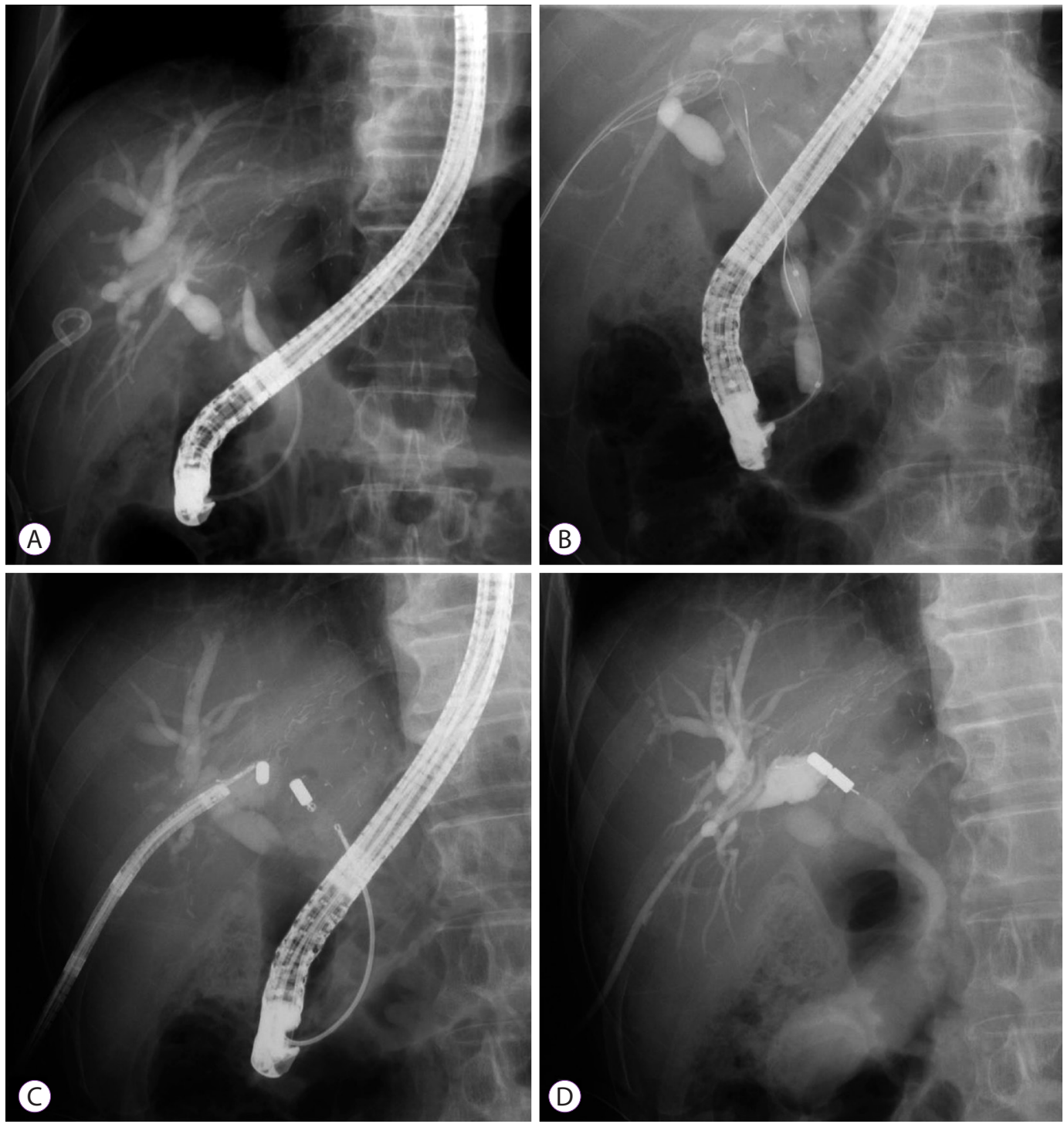

Fig. 3. Magnetic compression anastomosis in a 62-year-old man with a biliary stricture after living-donor liver transplant. (A) Endoscopic retrograde cholangiopancreatography (ERCP) showing the guide wire failing to pass through the anastomotic stricture. (B) After a percutaneous transhepatic biliary drainage (PTBD) catheter was inserted and the tract was dilated to $18 \mathrm{Fr}$, pneumatic dilatation was performed across the ampullary orifice. (C) A magnet was delivered via ERCP through the common bile duct, while another was inserted via the PTBD tract. (D) Fluoroscopy showing complete approximation of the magnets.

and improving patients' clinical conditions. In any case, both are effective and complementary therapies for LT-associated biliary complications. ${ }^{44}$

Magnetic compression anastomosis (MCA) was recently developed as another hybrid technique for resolving post-LDLT biliary duct-to-duct anastomosis strictures that cannot be resolved using conventional methods such as ERCP and PTCS. This technique can be applied in cases of completely obstructed or disconnected biliary strictures (Fig. 3). ${ }^{45}$ One study involving this technique achieved magnet approximation to the anastomosis stricture in $84 \%$ (10/12) of patients. With regard to MCA-related complications during the follow-up period (mean, 331 days; range, 148-581 days), there was one case of mild cholangitis and one case of ASs recurrence. ${ }^{46}$ Furthermore, two bilio-enteric MCA procedures have been used to treat ASs after LT that could not be crossed using the conventional guidewire method. During the follow-up period (54 months and 6 months, respectively), restenosis occurred in a single case 6 days after drainage tube removal, but this patient remained asymptomatic after additional balloon dilatation. ${ }^{47}$ The advantages of MCA are that it is less traumatic than surgical therapy and has a very low stricture recurrence rate. Therefore, MCA safely and effectively resolves difficult and completely obstructed post-LDLT biliary strictures. 

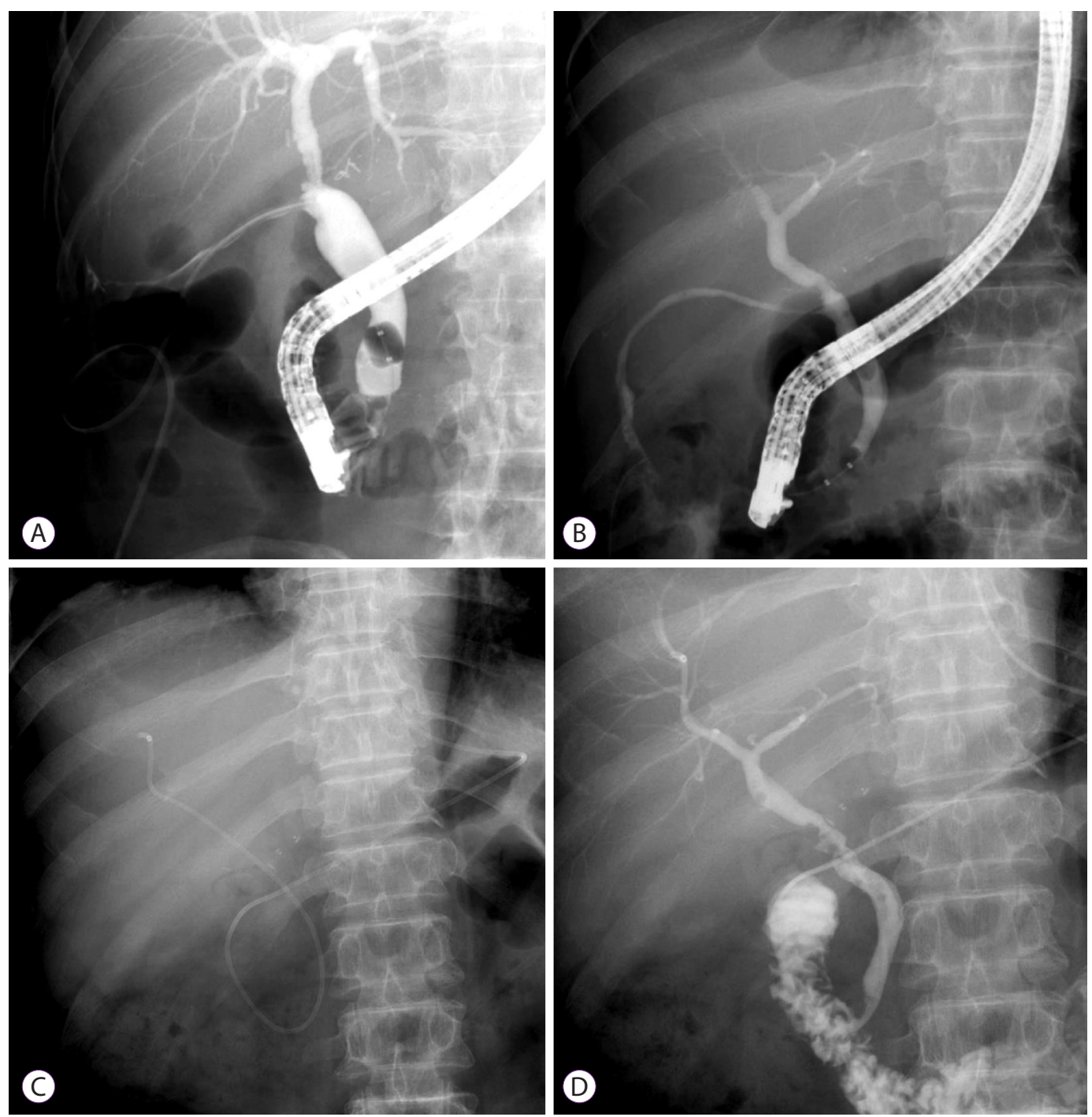

Fig. 4. Bile leakage in a 74-year-old man after a deceased-donor liver transplant. (A) Cholangiogram showing bile leakage along the T-tube tractwith the T-tube in situ. (B, C) Cholangiogram showing T-tube tract leakage after the T-tube removal as well as sphincterotomy and nasobiliary catheter across the leakage site. (C) Repeat cholangiogram 2 weeks later demonstrating no evidence of bile leakage.

\section{Bile leaks}

Most of the literature on bile leaks after LT surgery is old and revolves around the T-tube and its management. With the increasing prevalence of LDLT and the many modifications of DDLT, the pathogenesis of bile leaks has shifted to more technical factors; in this regard, T-tube related problems are now reported less frequently. The main factors contributing to bile leakage are partial or complete anastomosis site disruption, ischemic injury due to hepatic artery ischemia, and cut surface leakage at a bile duct tributary or T-tube insertion site. The prevalence of bile leaks does not differ significantly between DDLT and $\mathrm{LDLT}^{3}$ nor does anastomosis type (CC or $\mathrm{HJ}){ }^{6}$ The overall incidence of bile leakage is $2 \%-25 \%{ }^{3}$ Moreover, it is also important to recognize the association between bile leaks and bile duct strictures because bile leaks are an important factor in the development of biliary strictures in post-LDLT recipients-particularly older patients ( $>50$ years). ${ }^{10} \mathrm{~A}$ comprehensive review of 55 articles on the subject noted that the onset of biliary leak ranged from 1 day to 6 months after LT. Meanwhile, the incidence of the complication was 7.8\% (668/8585) among DDLT patients and 9.5\% (268/2812) among LDLT patients. ${ }^{4}$

Bile leaks can be classified as early (within 4 weeks of LT) and late ( $>4$ weeks after LT). ${ }^{3}$ Early leaks are typically associated with anastomotic leaks, local ischemic injury due to hepatic artery thrombosis, leakage around a T-tube insertion site (if present), or the cut surface of the liver after LDLT. Late bile leaks tend follow T-tube removal-up to $33 \%$ of such leaks occur at this point. ${ }^{9,48}$

Leaks at the T-tube insertion site can be treated conserva- 
tively and symptomatically. Indeed, one-third to one-half of such leaks close spontaneously within 24 hours. ${ }^{49}$ The majority of the remaining patients with bile leaks require non-operative diversion of biliary flow by the following measures: (1) unclamping of the T-tube; (2) endoscopic sphincterotomy with or without biliary stenting; (3) placement of a nasobiliary or percutaneous transhepatic biliary drainage (PTBD) catheter; or (4) a combination of any of these methods with high success rates. Most studies have reported symptom resolution in $>85 \%$ of patients. ${ }^{22,50,51}$ Historically, nasobiliary catheters were used successfully to treat post-OLT bile leaks (Fig. 4). ${ }^{44,51}$ In one study, among 551 reported cases of bile leakage (283 after DDLT and 268 after LDLT) with a clearly delineated treatment modality, ERCP was used in $38 \%$ of cases, surgical revision in $28 \%$ of cases, PTBD in $10 \%$ of cases, and observation in $34 \%$ of cases. Re-transplantation was not required in any cases, but 13 patients (1\%; 10 after DDLT and 3 after LDLT) died of secondary sepsis. ${ }^{4}$

ERCP, along with sphincterotomy and biliary stent placement, has become the preferred method to diagnose and treat bile leakage with high success rates and low complication rates. ${ }^{52,53}$ The stent is usually kept in place for several weeks to ensure adequate leak healing. After successful conservative management and in the absence of any pathology, the stent is removed. Small leaks can also be managed with sphincterotomy alone. ${ }^{54}$

CSEMSs have recently been used to treat biliary leaks that are refractory to conventional treatment. In one study, 35 patients with bile leaks were treated with fully and partially covered 8-10 mm diameter SEMSs that were subsequently removed. The median duration of stenting was 9 weeks, and 33 (94\%) of the bile leaks were resolved. ${ }^{55}$ PTCS is used in cases where ERCP cannot be performed or in patients who have undergone Roux-en-Y reconstruction, in which the biliary orifice cannot be reached using a regular side-view endoscope. Occasionally, PTCS may require internal-external biliary stent placement via interventional radiology, and patients may eventually require surgery to control the leaks. ${ }^{44,50}$

\section{Biliary stones and sludge}

Post-LT bile duct stones, sludge, and casts pose a formidable challenge to both patients and their treating physician because they have multiple pathogeneses, comorbidities, and management complexities. A multidisciplinary approach is usually the only way to improve success rates and outcomes, and multiple interventional resources are usually required to manage individual patients.

Biliary stones and sludge can occur at any time after LT, with a reported incidence of $5 \%-10 \% .{ }^{23}$ Furthermore, biliary strictures have been associated with stones and may be observed in up to $90 \%$ of patients with bile duct stones. ${ }^{56}$ In addition to biliary obstruction, kinking of the bile duct, mucosal damage, ischemia, infection, foreign bodies, cholesterol supersaturation, and bile acid pool depletion may also result in lithogenesis. ${ }^{57,58}$ Medications used in transplant patients may play a role in this regard since cyclosporine inhibits bile acid synthesis, thereby promoting stone formation. ${ }^{59}$ Elevated cholesterol levels (>200 mg/dL) and triglyceride levels (>150 $\mathrm{mg} / \mathrm{dL}$ ) lead to a marked increase in stone formation after LT, suggesting that hyperlipidemia should be aggressively treated in LT recipients. ${ }^{60}$ Occasionally, severe complications such as cholangitis and secondary biliary cirrhosis may occur as a result of stones and sludge. Furthermore, biliary cast syndrome requires a special mention; this is a distinct condition that is characterized by multiple, hard,pigmented stone casts within the bile ducts. The condition has been observed in post-transplant recipients, and it affects morbidity, graft failure, re-transplantation, and mortality rates. The reported incidence is $2.5 \%-18 \%{ }^{25,61}$ The pathogenesis of this condition is thought to be multifactorial: acute cellular rejection, ischemia, infection, and biliary obstruction due to stasis in patients with or without bile duct strictures are contributing factors. It is extremely important that physicians caring for patients with biliary cast syndrome remain vigilant, particularly because immunosuppressants and catastrophic late presentation tend to mask symptoms. As such, the syndrome often fails to manifest its typical clinical course and can lead to graft loss and mortality.

ERCP is the investigation of choice for most patients with post-LT bile duct stones, sludge, and casts. In this regard, several studies have reported success rates as high as $90 \%-100 \%$ for stone clearance and that most patients experience symptomatic, clinical, and liver biochemical improvements. ${ }^{44,62}$ Indeed, in patients with non-altered anatomy, a standard sphincterotomy followed by extraction balloon or extraction basket clearance of stones and sludge can be achieved without any major limitations using the conventional side-viewing ERCP scopes. ${ }^{36}$ In patients with an anatomy that has been altered by bilio-enteric anastomosis, the same can be achieved using modified longer enteroscopic versions. In cases of severe coagulopathy or thrombocytopenia, sphincterotomy may be contraindicated. Therefore, balloon dilation of the intact sphincter may be indicated. The removal of large bile duct stones and casts can be achieved using a combination of biliary sphincterotomy and large-balloon dilation of the biliary orifice. Such a combined procedure has improved efficacy and minimized complications. ${ }^{14}$ If biliary stricture occurs with stones, it should be treated simultaneously (Fig. 5). ${ }^{36}$

Proximally located stones and associated tortuous and long multiple strictures have always been a major limitation of the endoscopic management of post-LT bile duct complications. 

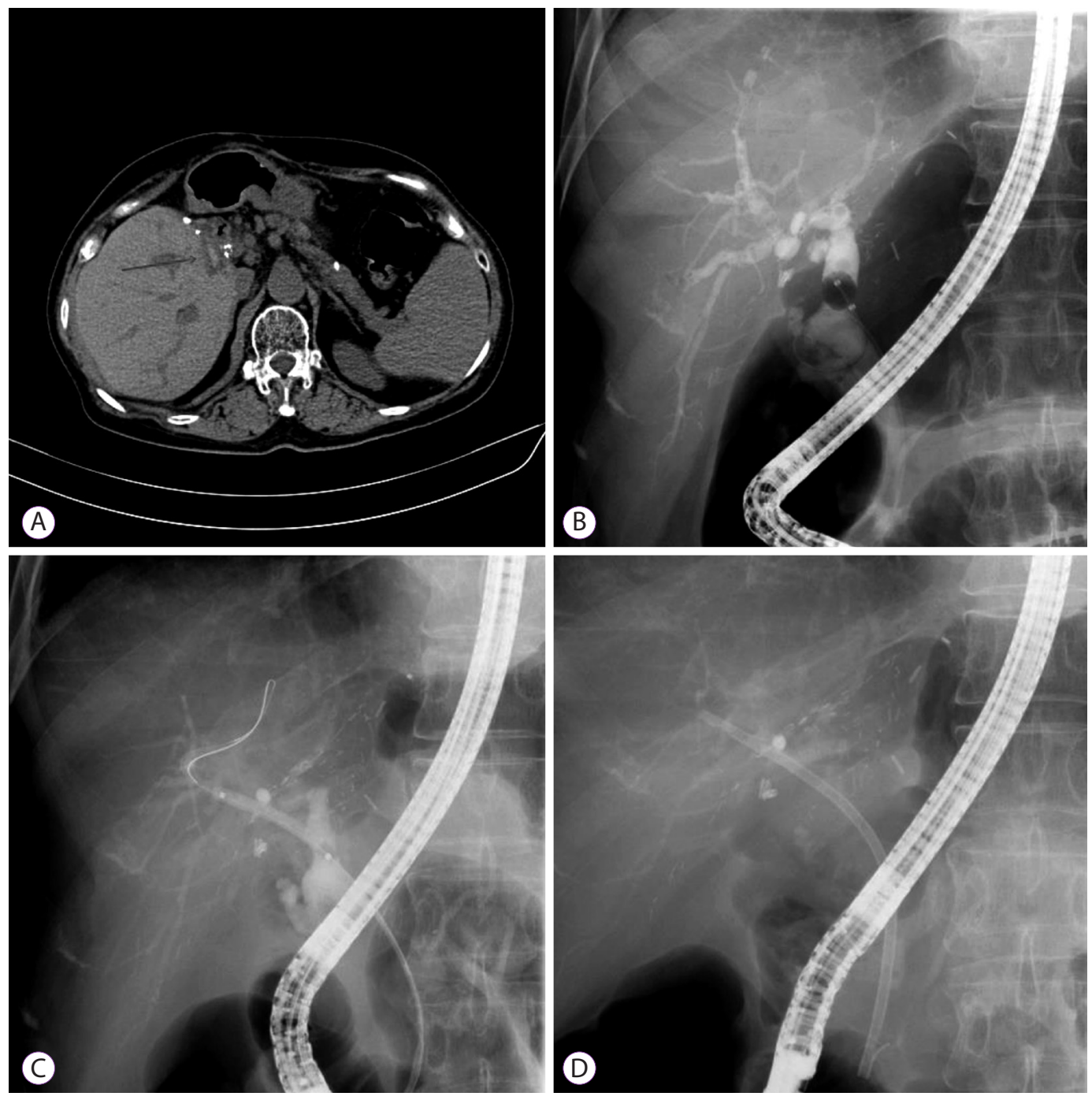

Fig. 5. Biliary stones and intrahepatic duct dilatation in a 59-year-old woman with anastomotic stricture (AS) after a living-donor liver transplant. (A) Computed tomography showing high-attenuation material at the hepatic hilum. (B) Cholangiogram showing an intraductal filling defect suggestive of a stone within the AS. (C, D) Balloon dilatation of the AS after stone removal and plastic stent insertion.

When direct cholangioscopy previously permitted access to the biliary tree through the conventional route, it allowed the management of difficult or complex proximal pathological stones, sludge, and associated strictures. This method was combined with advanced intraductal techniques that break down large stones, such as electrohydraulic lithotripsy (EHL) or holmium laser lithotripsy. ${ }^{14}$ Relatedly, since bile duct stones and sludge are associated with bile duct strictures, PTCS is considered the treatment of choice in patients for whom duct access is endoscopically difficult as well as in those with intractable strictures that cannot be traversed using a retrograde approach or rendezvous access combined with ERCP. In this regard, PTCS is especially successful in improving graft functioning by clearing sludge and stones, particularly when combined with basket and EHL stone fragmentation. Biliary stones can be removed using (1) mechanical basket lithotrip- sy through the PTBD tract or (2) the scope push method to the common bile duct (CBD). EHL can be used to treat large stones that are not successfully removed by the mechanical basket. In one recent study, 15 patients underwent PTCS for the following post-LT biliary complications: IHD stone (10 patients), CBD stone (one patient), biliary cast (one patient), and biliary stricture (three patients). The study found that the prevalence and severity of these complications in PTCS patients are significantly lower than those in patients who have undergone traditional radiological percutaneous transhepatic interventions. This obviates the need for additional radiological or surgical interventions. ${ }^{63}$ PTCS and internal-external stents play a role in patients with multiple intrahepatic biliary strictures as well as in those with stones, sludge, and casts. Indeed, they may be extremely useful for relieving jaundice and improving the clinical condition of such patients. ${ }^{44}$ The most 

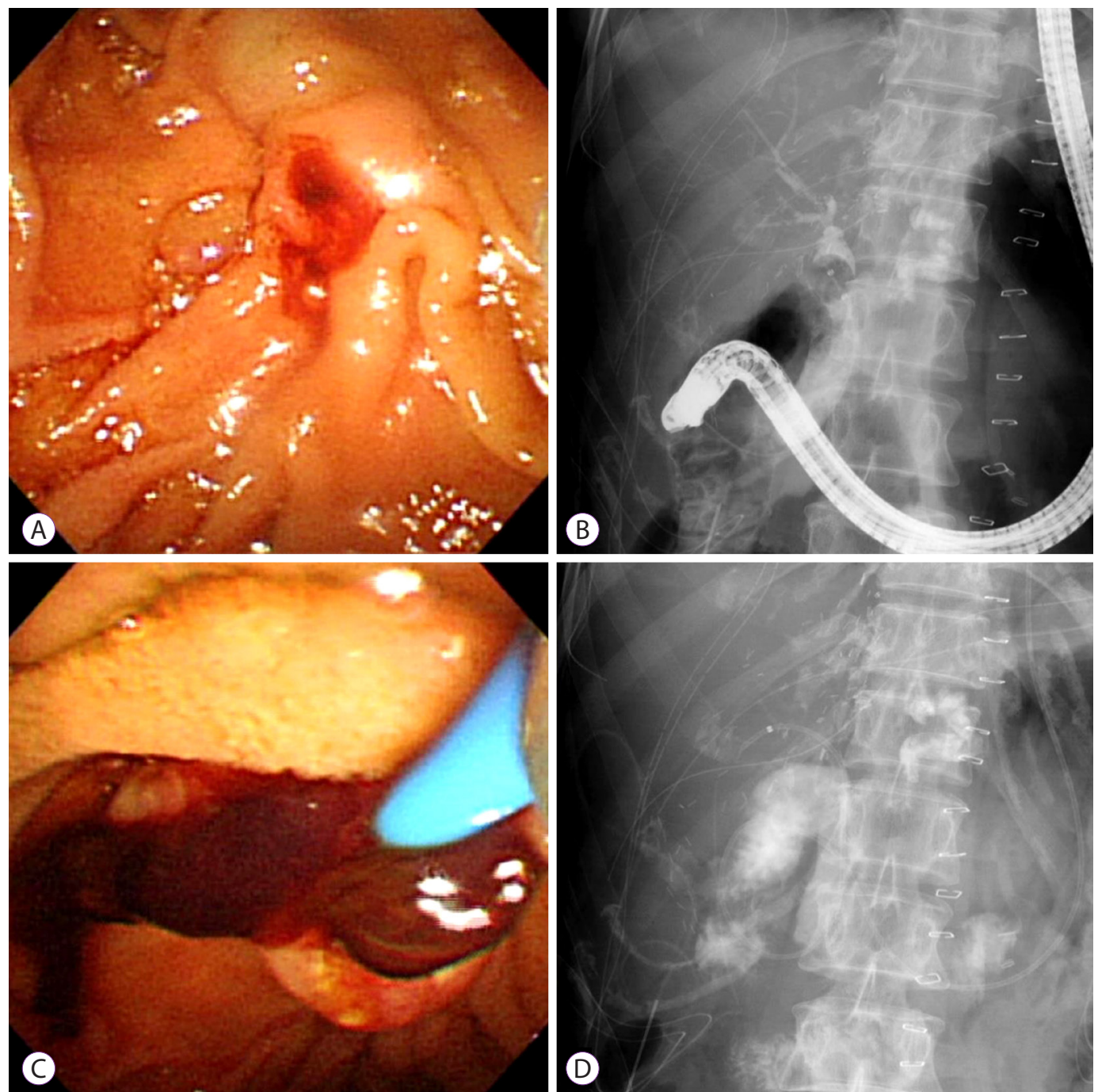

Fig. 6. Hemobilia in a 49-year-old woman after a living-donor liver transplant. (A) Running down of bloody bile at the ampullary orifice 2 days after the operation. (B, C) Cholangiogram showing an amorphous filling defect and a large blood clot on the retrieval balloon sweeping. (D) Sphincterotomy and nasobiliary catheter in the intrahepatic bile duct.

common limitation of PTCS and percutaneous approaches is significant patient discomfort; furthermore, the procedure is inconvenient because it requires frequent percutaneous catheter changes to enable remodeling.

\section{Hemobilia}

Hemobilia is an uncommon LT-related biliary complication with a frequency of $1.2 \%(33 / 2701){ }^{64}$ It is usually associated with percutaneous liver biopsy or PTCS through the creation of an arterio-biliary fistula. The pathogenesis of spontaneous hemobilia in the post-LT setting has not yet been elucidated. Nonetheless, blood clots in the bile duct can cause recurrent obstructive cholangitis and result in irreversible graft damage. The commonly described triad of right-upper-quadrant pain, jaundice, and gastrointestinal bleeding is only seen in a small proportion of patients. In LT patients, "United Network for
Organ Sharing" statuses I and IIa, alcoholic liver cirrhosis, and a body mass index $<24.5 \mathrm{~kg} / \mathrm{m}^{2}$ were significant risk factors for hemobilia. ${ }^{64}$ In rare cases, hemobilia has been associated with biliary stricture and multiple IHD stones have formed above the obstruction level. ${ }^{65}$

Treatment of hemobilia requires both hemostasis and the treatment of any associated biliary obstruction by clots. In some cases, the bleeding stops spontaneously after supportive therapy and the correction of coagulopathy. Alternatively, if the bleeding is persistent or severe, embolization of the bleeding vessel by interventional radiology is required ${ }^{66,67} \mathrm{Cli}-$ nicians may prefer to manage spontaneous hemobilia using non-surgical intervention (via either the endoscopic transpapillary or percutaneous approach) in LT patients. Endoscopic sphincterotomy and blood clot extraction for relieving obstruction is usually performed via ERCP. Nasobiliary drainage 

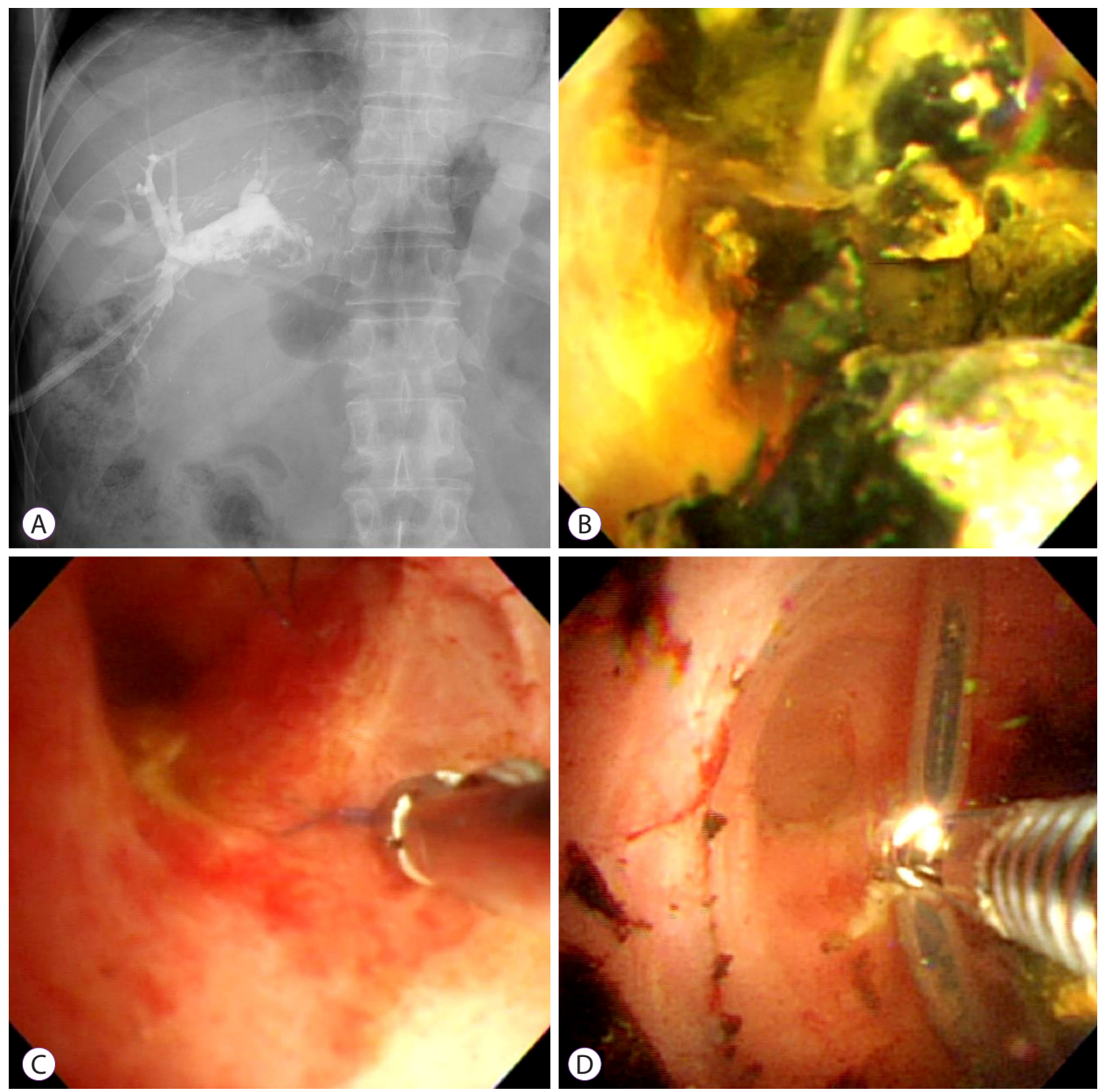

Fig. 7. Intrahepatic duct (IHD) stone and foreign bodies in a 65-year-oldman after a living-donor liver transplant. (A, B) Percutaneous transhepatic cholangioscopy image showing multiple intrahepatic stones. (C, D) Non-absorbable suture material that could act as a nidus for IHD stones as well as an indwelling catheter removed using forceps.

(NBD) catheters may promote blood clot lysis, slow bleeding, and prevent cholangitis by irrigation. Therefore, ERCP combined with sphincterotomy and an NBD catheter should be considered a primary choice in cases of hemobilia (Fig. 6). In one study, endoscopic NBD was performed in all patients with hemobilia, and 87.9\% (29/33) improved. ${ }^{64}$ On a different note, several case reports have stated that CSEMSs promote endoscopic hemostasis in cases of bleeding that cannot be controlled using conventional therapy. ${ }^{68}$ Indeed, CSEMSs may apply stronger pressure to the bile duct wall to achieve effective hemostasis; however, they may increase the risk of post-procedure pancreatitis. Recently, the placement of both an endoscopic biliary plastic stent (EBPS) and an NBD catheter has been shown to be an alternative hemostatic tool to SEMSs. The EBPS, combined with coagulation in the lumen, increases intrabiliary pressure. Therefore, biliary obstruction causes cholangitis. The combination of EBPS and an NBD catheter to prevent cholangitis is an alternative hemostatic tool to the CSEMS that reduces the risk of post-procedural pancreatitis. $^{69}$

In summary, post-LT hemobilia is not yet well defined as a disease entity, and most reported incidents are case studies only. Therefore, an additional large study is needed.

\section{Foreign bodies in bile ducts}

As mentioned above, PTCS has an advantage over ERCP in that it allows direct visualization of the biliary system for the identification and treatment of intraductal lesions. ${ }^{41}$ Foreign body material that has not clearly been seen in image studies-such as non-absorbable suture material, which that can act as a nidus for IHD stones-can be removed using PTCS. We successfully used PTCS to remove foreign bodies from the 
bile ducts of post-LT patients with bile duct stones, strictures, and sludge (Fig. 7).

\section{CONCLUSIONS}

Biliary tract complications remain common after LT despite improvements in operative techniques. Such complications remain a cause of morbidity and mortality. The endoscopic management of bile duct complications in the post-LT setting has evolved considerably with a consistent success rate of $>80 \%$ due to improvements in techniques, tools, and devices. Specifically, PTCS and POCS complement traditional ERCP for better and direct visualization and management of pathologies within the bile ducts, leading to improved clinical patient outcomes. Surgical and radiological intervention remains an option when endoscopic management fails. Additional effective new endoscopic techniques will become available in the future to increase optimal results.

\section{Conflicts of Interest}

The authors have no financial conflicts of interest.

\section{REFERENCES}

1. Balderramo D, Navasa M, Cardenas A. Current management of biliary complications after liver transplantation: emphasis on endoscopic therapy. Gastroenterol Hepatol 2011;34:107-115.

2. Brown RS Jr, Russo MW, Lai M, et al. A survey of liver transplantation from living adult donors in the United States. N Engl J Med 2003;348:818-825.

3. Kochhar G, Parungao JM, Hanouneh IA, Parsi MA. Biliary complications following liver transplantation. World J Gastroenterol 2013;19:2841-2846.

4. Akamatsu N, Sugawara Y, Hashimoto D. Biliary reconstruction, its complications and management of biliary complications after adult liver transplantation: a systematic review of the incidence, risk factors and outcome. Transpl Int 2011;24:379-392.

5. Scatton O, Meunier B, Cherqui D, et al. Randomized trial of choledochocholedochostomy with or without a $\mathrm{T}$ tube in orthotopic liver transplantation. Ann Surg 2001;233:432-437.

6. Greif F, Bronsther OL, Van Thiel DH, et al. The incidence, timing, and management of biliary tract complications after orthotopic liver transplantation. Ann Surg 1994;219:40-45.

7. Gyori GP, Schwarzer R, Püspök A, et al. Endoscopic versus surgical management of biliary complications - outcome analysis after 1188 orthotopic liver transplantations. Dig Liver Dis 2016.

8. Neuhaus P, Blumhardt G, Bechstein WO, Steffen R, Platz KP, Keck H. Technique and results of biliary reconstruction using side-to-side choledochocholedochostomy in 300 orthotopic liver transplants. Ann Surg 1994;219:426-434.

9. Scanga AE, Kowdley KV. Management of biliary complications following orthotopic liver transplantation. Curr Gastroenterol Rep 2007;9:3138.

10. Shah SA, Grant DR, McGilvray ID, et al. Biliary strictures in 130 consecutive right lobe living donor liver transplant recipients: results of a Western center. Am J Transplant 2007;7:161-167.
11. Ghobrial RM, Freise CE, Trotter JF, et al. Donor morbidity after living donation for liver transplantation. Gastroenterology 2008;135:468-476.

12. Azzam A, Uryuhara K, Taka I, Takada Y, Egawa H, Tanaka K. Analysis of complications in hepatic right lobe living donors. Ann Saudi Med 2010;30:18-24.

13. Pasha SF, Harrison ME, Das A, et al. Endoscopic treatment of anastomotic biliary strictures after deceased donor liver transplantation: outcomes after maximal stent therapy. Gastrointest Endosc 2007;66:44-51.

14. Arain MA, Attam R, Freeman ML. Advances in endoscopic management of biliary tract complications after liver transplantation. Liver Transpl 2013;19:482-498.

15. Attam R, Leslie D, Freeman M, Ikramuddin S, Andrade R. EUS-assisted, fluoroscopically guided gastrostomy tube placement in patients with Roux-en-Y gastric bypass: a novel technique for access to the gastric remnant. Gastrointest Endosc 2011;74:677-682.

16. Di Pisa M, Miraglia R, Volpes R, Gruttadauria S, Traina M. Single balloon enteroscopy for endoscopic retrograde cholangiography in a patient with hepaticojejunostomy after liver transplant. Gastroenterol Res Pract 2010;2010:701696.

17. Haruta H, Yamamoto H, Mizuta K, et al. A case of successful enteroscopic balloon dilation for late anastomotic stricture of choledochojejunostomy after living donor liver transplantation. Liver Transpl 2005;11:1608-1610

18. Saleem A, Baron TH. Successful endoscopic treatment of biliary cast syndrome in an orthotopic liver transplant patient with a Roux-en-Y anastomosis via balloon enteroscopy. Liver Transpl 2010;16:527-529.

19. Sanada Y, Mizuta K, Yano T, et al. Double-balloon enteroscopy for bilioenteric anastomotic stricture after pediatric living donor liver transplantation. Transpl Int 2011;24:85-90.

20. Shah RJ, Smolkin M, Yen R, et al. A multicenter, U.S. experience of single-balloon, double-balloon, and rotational overtube-assisted enteroscopy ERCP in patients with surgically altered pancreaticobiliary anatomy (with video). Gastrointest Endosc 2013;77:593-600.

21. Kim TH, Lee SK, Han JH, et al. The role of endoscopic retrograde cholangiography for biliary stricture after adult living donor liver transplantation: technical aspect and outcome. Scand J Gastroenterol 2011;46:188196.

22. Morelli J, Mulcahy HE, Willner IR, Cunningham JT, Draganov P. Longterm outcomes for patients with post-liver transplant anastomotic biliary strictures treated by endoscopic stent placement. Gastrointest Endosc 2003;58:374-379.

23. Ayoub WS, Esquivel CO, Martin P. Biliary complications following liver transplantation. Dig Dis Sci 2010;55:1540-1546.

24. Rerknimitr R, Sherman S, Fogel EL, et al. Biliary tract complications after orthotopic liver transplantation with choledochocholedochostomy anastomosis: endoscopic findings and results of therapy. Gastrointest Endosc 2002;55:224-231.

25. Sharma S, Gurakar A, Jabbour N. Biliary strictures following liver transplantation: past, present and preventive strategies. Liver Transpl 2008;14:759-769.

26. Solmi L, Cariani G, Leo P, Miracolo A, Nigro G, Roda E. Results of endoscopic retrograde cholangiopancreatography in the treatment of biliary tract complications after orthotopic liver transplantation: our experience. Hepatogastroenterology 2007;54:1004-1008.

27. Costamagna G, Pandolfi M, Mutignani M, Spada C, Perri V. Long-term results of endoscopic management of postoperative bile duct strictures with increasing numbers of stents. Gastrointest Endosc 2001;54:162-168.

28. Tabibian JH, Asham EH, Han S, et al. Endoscopic treatment of postorthotopic liver transplantation anastomotic biliary strictures with maximal stent therapy (with video). Gastrointest Endosc 2010;71:505512.

29. Vandenbroucke F, Plasse M, Dagenais M, Lapointe R, Lêtourneau R, Roy A. Treatment of post liver transplantation bile duct stricture with self-expandable metallic stent. HPB (Oxford) 2006;8:202-205.

30. Haapamäki C, Udd M, Halttunen J, Lindström O, Mäkisalo H, Kylän- 
pää L. Endoscopic treatment of anastomotic biliary complications after liver transplantation using removable, covered, self-expandable metallic stents. Scand J Gastroenterol 2012;47:116-121.

31. Park DH, Lee SS, Lee TH, et al. Anchoring flap versus flared end, fully covered self-expandable metal stents to prevent migration in patients with benign biliary strictures: a multicenter, prospective, comparative pilot study (with videos). Gastrointest Endosc 2011;73:64-70.

32. Traina M, Tarantino I, Barresi L, et al. Efficacy and safety of fully covered self-expandable metallic stents in biliary complications after liver transplantation: a preliminary study. Liver Transpl 2009;15:1493-1498.

33. Kaffes A, Griffin S, Vaughan R, et al. A randomized trial of a fully covered self-expandable metallic stent versus plastic stents in anastomotic biliary strictures after liver transplantation. Therap Adv Gastroenterol 2014;7:64-71.

34. Kao D, Zepeda-Gomez S, Tandon P, Bain VG. Managing the post-liver transplantation anastomotic biliary stricture: multiple plastic versus metal stents: a systematic review. Gastrointest Endosc 2013;77:679-691.

35. Chang JH, Lee IS, Chun HJ, et al. Usefulness of the rendezvous technique for biliary stricture after adult right-lobe living-donor liver transplantation with duct-to-duct anastomosis. Gut Liver 2010;4:68-75.

36. Shin M, Joh JW. Advances in endoscopic management of biliary complications after living donor liver transplantation: comprehensive review of the literature. World J Gastroenterol 2016;22:6173-6191.

37. Chang JH, Lee IS, Chun HJ, et al. Comparative study of rendezvous techniques in post-liver transplant biliary stricture. World J Gastroenterol 2012;18:5957-5964.

38. Zoepf T, Maldonado de Dechêne EJ, Dechêne A, et al. Optimized endoscopic treatment of ischemic-type biliary lesions after liver transplantation. Gastrointest Endosc 2012;76:556-563.

39. Gürakar A, Wright H, Camci C, Jaboour N. The application of Spy$\mathrm{Scope}^{\circ}$ technology in evaluation of pre and post liver transplant biliary problems. Turk J Gastroenterol 2010;21:428-432.

40. Wright H, Sharma S, Gurakar A, Sebastian A, Kohli V, Jabbour N. Management of biliary stricture guided by the Spyglass direct visualization system in a liver transplant recipient: an innovative approach. Gastrointest Endosc 2008;67:1201-1203.

41. Choi JH, Lee SK. Percutaneous transhepatic cholangioscopy: does its role still exist? Clin Endosc 2013;46:529-536.

42. Kim JH, Lee SK, Kim MH, et al. Percutaneous transhepatic cholangioscopic treatment of patients with benign bilio-enteric anastomotic strictures. Gastrointest Endosc 2003;58:733-738.

43. Choo SW, Shin SW, Do YS, et al. The balloon dilatation and large profile catheter maintenance method for the management of the bile duct stricture following liver transplantation. Korean J Radiol 2006;7:41-49.

44. Park JS, Kim MH, Lee SK, et al. Efficacy of endoscopic and percutaneous treatments for biliary complications after cadaveric and living donor liver transplantation. Gastrointest Endosc 2003;57:78-85.

45. Itoi T, Yamanouchi E, Ikeuchi N, Kasuya K, Iwamoto H, Tsuchida A. Magnetic compression duct-to-duct anastomosis for biliary obstruction in a patient with living donor liver transplantation. Gut Liver 2010;4 Suppl 1:S96-S98.

46. Jang SI, Kim JH, Won JY, et al. Magnetic compression anastomosis is useful in biliary anastomotic strictures after living donor liver transplantation. Gastrointest Endosc 2011;74:1040-1048.

47. Muraoka N, Uematsu H, Yamanouchi E, et al. Yamanouchi magnetic compression anastomosis for bilioenteric anastomotic stricture after living-donor liver transplantation. J Vasc Interv Radiol 2005;16:1263-1267.

48. Ostroff JW, Roberts JP, Gordon RL, Ring EJ, Ascher NL. The management of $\mathrm{T}$ tube leaks in orthotopic liver transplant recipients with endoscopically placed nasobiliary catheters. Transplantation 1990;49:922-924.

49. Shuhart MC, Kowdley KV, McVicar JP, et al. Predictors of bile leaks after T-tube removal in orthotopic liver transplant recipients. Liver Trans- pl Surg 1998;4:62-70.

50. Johnston TD, Gates R, Reddy KS, Nickl NJ, Ranjan D. Nonoperative management of bile leaks following liver transplantation. Clin Transplant 2000;14(4 Pt 2):365-369.

51. Oh DW, Lee SK, Song TJ, et al. Endoscopic management of bile leakage after liver transplantation. Gut Liver 2015;9:417-423.

52. Dumonceau JM, Tringali A, Blero D, et al. Biliary stenting: indications, choice of stents and results: European society of gastrointestinal endoscopy (ESGE) clinical guideline. Endoscopy 2012;44:277-298.

53. Thuluvath PJ, Atassi T, Lee J. An endoscopic approach to biliary complications following orthotopic liver transplantation. Liver Int 2003;23:156162.

54. Llach J, Bordas JM, Elizalde JI, et al. Sphincterotomy in the treatment of biliary leakage. Hepatogastroenterology 2002;49:1496-1498.

55. Irani S, Baron TH, Law R, et al. Endoscopic treatment of nonstricture-related benign biliary diseases using covered self-expandable metal stents. Endoscopy 2015;47:315-321.

56. Starzl TE, Putnam CW, Hansbrough JF, Porter KA, Reid HA. Biliary complications after liver transplantation: with special reference to the biliary cast syndrome and techniques of secondary duct repair. Surgery 1977;81:212-221.

57. Farouk M, Branum GD, Watters CR, et al. Bile compositional changes and cholesterol stone formation following orthotopic liver transplantation. Transplantation 1991;52:727-730.

58. Waldram R, Williams R, Calne RY. Bile composition and bile cast formation after transplantation of the liver in man. Transplantation 1975;19:382-387.

59. Rotolo FS, Branum GD, Bowers BA, Meyers WC. Effect of cyclosporine on bile secretion in rats. Am J Surg 1986;151:35-40.

60. Gisbert C, Prieto M, Berenguer M, et al. Hyperlipidemia in liver transplant recipients: prevalence and risk factors. Liver Transpl Surg 1997;3:416-422.

61. Krok KL, Cardenas A, Thuluvath PJ. Endoscopic management of biliary complications after liver transplantation. Clin Liver Dis 2010;14:359-371.

62. Pfau PR, Kochman ML, Lewis JD, et al. Endoscopic management of postoperative biliary complications in orthotopic liver transplantation. Gastrointest Endosc 2000;52:55-63.

63. Nam K, Lee SK, Song TJ, et al. Percutaneous transhepatic cholangioscopy for biliary complications after liver transplantation: a single center experience. J Hepatobiliary Pancreat Sci 2016;23:650-657.

64. Park TY, Lee SK, Nam K, et al. Spontaneous hemobilia after liver transplantation: frequency, risk factors, and outcome of endoscopic management. J Gastroenterol Hepatol 2016 Jul 23 [Epub]. https://doi. org/10.1111/jgh.13497.

65. Pitre J, Dousset B, Massault PP, Soubrane O, Legmann P, Houssin D. Multiple intrahepatic stones caused by hemobilia in liver transplant recipients. Surgery 1997;121:352-354.

66. Feng W, Yue D, ZaiMing L, et al. Iatrogenic hemobilia: imaging features and management with transcatheter arterial embolization in 30 patients. Diagn Interv Radiol 2016;22:371-377.

67. Zajko AB, Chablani V, Bron KM, Jungreis C. Hemobilia complicating transhepatic catheter drainage in liver transplant recipients: management with selective embolization. Cardiovasc Intervent Radiol 1990;13:285-288.

68. Goenka MK, Harwani Y, Rai V, Goenka U. Fully covered self-expandable metal biliary stent for hemobilia caused by portal biliopathy. Gastrointest Endosc 2014;80:1175.

69. Shinjo K, Matsubayashi H, Matsui T, et al. Biliary hemostasis using an endoscopic plastic stent placement for uncontrolled hemobilia caused by transpapillary forceps biopsy (with video). Clin J Gastroenterol 2016;9:86-88. 